\title{
Small molecule inhibitors of a human recombination-associated ATPase, RAD54
}

\author{
Kirk T. Ehmsen ${ }^{1}$, Kenny K.H. Ang 3 , William D. Wright ${ }^{1}$, Julia L. Davies ${ }^{3}$, Yassir Younis ${ }^{3}$, \\ Yuliya Birman ${ }^{3}$, Clifford Bryant ${ }^{3}$, Alejandra Gallardo-Godoy ${ }^{3}$, Adam R. Renslo ${ }^{3}$, R. Jeffrey \\ Neitz ${ }^{3}$, Michelle R. Arkin ${ }^{3}$ and Wolf-Dietrich Heyer ${ }^{1,2, *}$
}

${ }^{1}$ Department of Microbiology and Molecular Genetics, University of California at Davis, Davis, CA, 95616-8665, USA

${ }^{2}$ Department of Molecular and Cellular Biology, University of California at Davis, Davis, CA, 95616-8665, USA

${ }^{3}$ Department of Pharmaceutical Chemistry and Small Molecule Discovery Center, University of California at San Francisco, San Francisco, CA, 94143-2280, USA

* To whom correspondence should be addressed. Tel: + 1530 752-3001; Fax: +1 530 752-3011; Email: wdheyer@ucdavis.edu

Present Addresses: Kirk Ehmsen, Department of Cellular and Molecular Pharmacology, University of California at San Francisco, San Francisco, CA, 94143-2280, USA

Yassir Younis, MyoKardia, South San Francisco, CA, 94080, USA

Alejandra Gallardo-Godoy, Institute for Molecular Bioscience, The University of Queensland, Brisbane, QLD, 4072, Australia

Keywords: RAD54, ATPase, recombination, carbazole, high-throughput screen

Short title: Human RAD54 ATPase inhibitors 


\begin{abstract}
Homologous recombination (HR) is a principal support pathway for DNA replication and for recovery from DNA breaks and interstrand crosslinks, making it a rational target for inhibition in cancer therapy. The ATPase RAD54 functions in molecular events that promote DNA sequencepreservation during HR-mediated damage repair, including homology search, DNA strand exchange, and transition to DNA repair synthesis within a displacement loop intermediate. We developed a high-throughput biochemical screen to identify small-molecule inhibitors of human RAD54, using a phosphate detection assay to monitor RAD54 ATPase activity in the presence of double-stranded DNA (dsDNA). After filtering potential DNA intercalators and 'frequent hitters,' we identified two chemotypes that reproducibly inhibited RAD54 ATPase in vitro. We evaluated these chemotypes for inhibition of RAD54-dsDNA binding and cancer cell survival. A halogenated carbazole/dihydroacridine scaffold inhibited a panel of SWI2/SNF2 -related ATPases but not VCP/p97, an unrelated ATPase. Small molecules that interfere with key steps in HRsuch as inhibitors of RAD54-may expose DNA repair-dependent vulnerabilities in cancer cells.
\end{abstract}

\title{
INTRODUCTION
}

Homologous recombination (HR) is an evolutionarily ancient DNA repair pathway with functions in replication-fork support, DNA double-strand break repair and interstrand crosslink repair ${ }^{1}$. Some cancers exploit HR for survival when confronted with intrinsic replication stress, deficient alternative repair pathways, and/or chemotherapeutic- and radiation-induced DNA damage ${ }^{2,3}$. Hence, genetic or chemical disruption of critical steps in HR could kill cancer cells that have inherent DNA-repair deficiencies, and could sensitize cells to treatments that cause DNA damage or interfere with replication ${ }^{4,5}$. 
In HR, a span of single-stranded DNA (ssDNA) references a related DNA sequence elsewhere in the genome to restore lost or damaged sequence information. In eukaryotes, the ATPases RAD51 and RAD54 are required for homology search, recognition, and DNA strand exchange ${ }^{6}$. RAD51, RAD51 paralogs and associated factors assemble on ssDNA, creating a nucleoprotein filament that catalyzes the identification of a homologous double-stranded DNA (dsDNA) sequence, typically at an allelic site. Base-pairing between the RAD51-coated ssDNA and its dsDNA complement results in DNA strand exchange, the conversion of a RAD51-bound filament and its dsDNA target to a RAD51-bound heteroduplex DNA (hDNA) within a displacement loop (D-loop) ${ }^{7}$. When RAD51 dissociates from hDNA, the 3'-hydroxyl of the invading ssDNA can prime DNA synthesis, using the complementary strand in the hDNA as a template to restore missing sequence. Diverse protein factors regulate RAD51 filament assembly, homology search, DNA strand exchange, and the transition to DNA repair synthesis ${ }^{8}$, suggesting that multiple enzymes and stages in HR could be targeted for inhibition in cancer cells.

At the key transition between homologous sequence identification and DNA repair synthesis, Dloop formation and RAD51 dissociation from hDNA are catalyzed by RAD54 ${ }^{9}$, a dsDNAdependent, multimeric ATPase that functionally associates with the RAD51 nucleoprotein filament ${ }^{10,11}$. Whereas RAD51 exhibits slow ATPase kinetics on both ssDNA and dsDNA (kcat $\sim 0.4$ ATP RAD51-1 $\mathrm{min}^{-1}$ ), RAD54 hydrolyzes ATP only in the presence of dsDNA, with roughly 2,500-fold faster kinetics than RAD51 (kcat $\sim 10^{3}$ ATP RAD54 $\left.{ }^{-1} \mathrm{~min}^{-1}\right)^{12-14}$. Both ATPases coordinate the transition from synapsis (defined by a RAD51-bound, three-stranded DNA intermediate) to post-synapsis (hDNA 3'-terminus competent to prime DNA repair synthesis), as RAD54 specifically dissociates the ADP-bound conformation of RAD51 ${ }^{1,12}$ and RAD54 ATPase activity is stimulated by interaction with RAD51 on dsDNA ${ }^{15}$. RAD54 modulation of RAD51- 
dsDNA interaction is consistent with the hallmark activities of eukaryotic SWI2/SNF2 ATPases, namely remodeling of specific protein-DNA interactions ${ }^{16}$. In vivo studies in Saccharomyces cerevisiae demonstrate that although Rad51 filaments assemble and Rad51 can be recovered from donor loci in the absence of Rad54, DNA synthesis from the donor template requires the ATPase activity of $\operatorname{Rad} 54^{17}$. Altogether, these observations suggest that RAD54 is a critical modulator of transitional step(s) between homologous pairing and the synthesis-dependent recovery of homologous sequence.

We sought to discover small-molecule inhibitors of RAD54 to seed an anti-cancer drugdiscovery effort. Using a colorimetric malachite green phosphate detection assay ${ }^{18}$, we screened $>106,000$ small molecules for inhibition of ATPase activity in the presence of dsDNA, and retested 310 molecules from the primary screen using an orthogonal luminescent ATPase assay that reports on ADP levels (ADP-Glo ${ }^{\mathrm{TM}}$ ). Compounds with activity in both assays were evaluated for DNA-binding and chemical tractability. Two chemical scaffolds $(54 \mathrm{i}-1,54 \mathrm{i}-2)$ that i) reproducibly interfered with RAD54 ATPase, ii) were not DNA-binders, and iii) passed PAINS filters, were evaluated for i) reversibility/irreversibility of ATPase inhibition, ii) effect on RAD54dsDNA binding, and iii) toxicity to immortalized cancer lines. A halogenated carbazole (54i-1) and related dihydroacridine analogs were identified as inhibitors of RAD54 and related SWI2/SNF2 ATPases.

\section{MATERIALS AND METHODS}

Human RAD54 purification and ATPase activity - Human RAD54 was purified as a GST-fusion from baculovirus-infected Sf9 cells; ATPase activity was entirely dsDNA-dependent and promoted D-loop formation with RAD51 in vitro as previously described ${ }^{14,19}$. 
Malachite green (MG) primary assay-A pilot screen of 1,995 bioactive molecules (MicroSource Spectrum) and full-scale screen of 104,286 chemically diverse small molecules (commercial vendors) were performed in transparent 384-well microplates (Greiner Bio-One). In each plate, 32 wells served as positive controls for 100\% ATPase inhibition (-DNA, +RAD54, +DMSO), 32 served as negative controls for 0\% ATPase inhibition (+DNA, +RAD54, +DMSO), and 320 accommodated test compounds (+DNA, +RAD54, +compound in DMSO). $25 \mu \mathrm{L}$ of Solution I reaction buffer (25 mM HEPES, pH 7.5, $3 \mathrm{mM} \mathrm{Mg(OAc)} 2,1 \mathrm{mM}$ DTT, $30 \mu \mathrm{g} / \mathrm{mL}$ BSA, 0.1\% CHAPS, 2.5 nM RAD54 (monomer), \pm 125 nM (bp) pUC19 DNA (NEB)) was added to each well, using a Matrix Wellmate fitted with Matrix WellMate Disposable Tubing Assembly (8-channel small-bore nozzle; ThermoScientific). For test wells, $50 \mathrm{~nL}$ compound was added to a final assay concentration of $10 \mu \mathrm{M}$ using a Biomek FXp Laboratory Automated Workstation fitted with 50 $\mathrm{nL}$ pintool (V\&P Scientific). ATPase assays were initiated by adding $25 \mu \mathrm{L}$ of Solution II reaction buffer (like Solution I but +ATP, -DNA, -RAD54) to each well, bringing the final concentration to $2.5 \mathrm{nM}$ RAD54 (monomer), $1 \mathrm{mM}$ ATP, $125 \mathrm{nM}$ (bp) pUC19, 0.1\% DMSO, and $10 \mu \mathrm{M}$ compound. Final DNA:RAD54 ratios were 50 bp:1 RAD54 monomer. Plates were incubated for 13-14 minutes at room temperature (RT). ATPase activity was stopped by adding $15 \mu \mathrm{L} 5.33 \mathrm{X}$ malachite green developing mix $\left(1.6 \%\left(\mathrm{NH}_{4}\right)_{6} \mathrm{Mo}_{7} \mathrm{O}_{24} .4 \mathrm{H}_{2} \mathrm{O}\right.$ [ammonium molybdate], $0.16 \%$ malachite green, 4.26 M HCl, and 1.07\% polyvinyl acetate [PVA]) to a final assay concentration of $0.3 \%$ ammonium molybdate, $0.03 \%$ malachite green, $0.8 \mathrm{M} \mathrm{HCl}$, and $0.2 \%$ polyvinyl acetate. After 1-2 minutes, color development was quenched with $15 \mu \mathrm{L} 6 \% \mathrm{Na}_{3} \mathrm{C}_{6} \mathrm{H}_{5} \mathrm{O}_{7}$ (final assay concentration of $1.5 \%$ sodium citrate, $5: 1$ citrate:molybdate ratio). Developing reagent and quench reagent were delivered sequentially by an EL406 automated multi-channel liquid dispenser with 5 $\mu \mathrm{L}$ Dispense Cassette (BioTek). Absorbance was determined at $\lambda=620 \mathrm{~nm}$ (A620) in an 
AnalystHT multimode plate reader (Molecular Devices). Data were processed, stored and retrieved using the Small Molecule Discovery Center's (SMDC) database and web interface, HiTS (https://hits.ucsf.edu). Data were analyzed in GraphPad Prism version 5.0 for Mac OS X as column scatter plots (vertical) with column statistics returned to report mean, standard deviation and median (GraphPad Software).

ADP-Glo ${ }^{\text {TM }}$ secondary assay-ADP-Glo ${ }^{\mathrm{TM}}$ assay was performed following manufacturer's instructions (Promega), except ATPase activity was stopped with $16.5 \mu \mathrm{L}$ ADP-Glo ${ }^{\mathrm{TM}}$ reagent and $33 \mu \mathrm{L}$ kinase detection reagent at 45 minutes (1 reaction volume:0.33 ADP-Glo reagent:0.66 kinase detection reagent). Luminescence was measured in an AnalystHT plate reader.

IC $C_{50}$ calculations - Inhibition dose response was evaluated at seven compound concentrations spanning $0.31-20 \mu \mathrm{M}$ (for $\mathrm{MG),} 0.63-30 \mu \mathrm{M}$ (for ADP-Glo ${ }^{\mathrm{TM}}$ ), or $0.078-60 \mu \mathrm{M}$ (repurchased or resynthesized compounds), with $\mathrm{IC}_{50}$ calculated in GraphPad Prism using the "nonlinear regression $\log$ (inhibitor) vs. response-variable slope (four parameters)' equation, with bottom constraint set to 'constant equal to 0 ' and top constraint set to 'constant equal to 100.' Hit compounds were repurchased in 1-20 mg units from ChemBridge (5), Specs (1), InterBioScreen (4), ChemDiv (3), VitasMLab (8), ASINEX (2), Princeton (2), or Sigma (1) (Supp. Table 8).

Hit evaluation to filter potential dsDNA intercalators-DNA intercalators inhibit RAD54 ATPase activity, as confirmed using the MG screening assay (see Supplement for details). Intercalation of screening hits was therefore measured in two assays. First, the $\mathrm{IC}_{50}$ was determined at two separate DNA concentrations (125 nM pUC19 [bp] vs. 125,000 nM pUC19 [bp]). Second, intercalation-based inhibition of plasmid supercoiling was monitored by TopoI inhibition; supercoiled pUC19 was incubated with compound at 5 concentrations $(0.1-50 \mu \mathrm{M}$, Class III compounds) or 1 concentration (50 $\mu \mathrm{M}$, Class I and II compounds) for 15 minutes, RT. 
2.5 U E. coli TopoI was added and incubated for 45 minutes, $37^{\circ} \mathrm{C}^{20}$. After deproteinization with $0.25 \% \mathrm{SDS} / 250 \mu \mathrm{g} / \mathrm{mL}$ proteinase $\mathrm{K}$ for 30 minutes at $50{ }^{\circ} \mathrm{C}$, samples were electrophoresed on a 1\% agarose-TBE gel, EtBr-stained, and imaged (UV, Alpha Innotech FluorChem ${ }^{\text {TM }} 8900$ ).

PAINS and frequent hitter prediction-We evaluated 158 hits (compounds inhibitory to RAD54 in both $\mathrm{MG}$ and ADP-Glo ${ }^{\mathrm{TM}}$ assays) for PAINS substructures across three cheminformatics technologies: HiTS (SMDC), Filter-it ${ }^{\mathrm{TM}}$ 1.0.2 (Silicos-it), and OpenEye (OpenEye Scientific). For HiTS, PAINS substructures were converted from SLN format to SMARTS patterns ${ }^{21}$, then mapped to the hit structures and flagged using Pipeline Pilot (Biovia, San Diego, CA) (https://doi.org/10.7272/Q6ZP449V); standardized SMILES strings were additionally tested against the Lilly-Medchem-Rules (https://github.com/IanAWatson/Lilly-Medchem-Rules, Eli Lilly and Company, Indianapolis, IN) for identifying potential frequent hitters using Pipeline Pilot ${ }^{22}$ (https://doi.org/10.7272/Q6V122Z9). For Filter-it ${ }^{\mathrm{TM}}$, SDF files were converted from SMILES string text files in Open Babel and hits with PAINS substructures were flagged with filter=PAINS.sieve ${ }^{23}$. For OpenEye, hit structures were passed through the toolkit's PAINS filter using a custom Python script (https://doi.org/10.7272/Q6Q81B8F).

Reversibility assay - Reversibility of ATPase inhibition was determined by monitoring recovery of RAD54 activity following 100-fold dilution of an enzyme-inhibitor complex formed at $250 \mathrm{nM}$ RAD54 (monomer) +inhibitor at ten-fold $\mathrm{IC}_{50}$. Following incubation in $5 \mu \mathrm{L}$ for 15 minutes at RT, ATPase reaction was initiated with $495 \mu \mathrm{L}$ Solution I (-RAD54, +DNA). $50 \mu \mathrm{L}$ volumes were removed at $0,5,10,15,20,30,45,60$ and 120 minutes, and mixed into $15 \mu \mathrm{L} \mathrm{MG}$ developing reagent pre-aliquoted to wells of a 384-well plate. MG assay was quenched with $15 \mu \mathrm{L} 6 \%$ NaCitrate 2.5-3 minutes later and A620 measured in SpectraMax M5 (Molecular Devices). 
DNA-binding assays - To determine the electrophoretic mobility shift midpoint (EMSM) for RAD54, 100 ng HindIII-linearized pUC19 (15.3 $\mu \mathrm{M}$ bp/5.7 $\mathrm{nM}$ molecules) and varying concentrations of RAD54 (1:500-1:10 RAD54:bp) were incubated for 20 minutes at RT in Solution I ( $\pm 1 \mathrm{mM}$ ATP). Mixtures were then taken to $\%$ Ficoll-70/0.25\% bromophenol blue and electrophoresed on $0.8 \%$ agarose-TAE gel, $50 \mathrm{~V}, \sim 2.5 \mathrm{~h}$, stained, and imaged. In subsequent assays, RAD54 was set to 1:25 RAD54:bp and compound titrated $(0.1-50 \mu \mathrm{M})$.

$S_{50}$ for chronic treatment (concentration with response $1 / 2$-between basal and maximal) —Cells were plated in DMEM supplemented with 10\% FBS, 1:200 penicillin/streptomycin (HEK293, MDA-MB-231, MCF7, ZR-75-1, VU423T, A9.13.423, U2OS, Saos2, LOX, HCT1080), 10\% horse serum, insulin and cholera toxin (MCF10A), or RPMI 1640 (HCC 1806), at $2 \times 10^{3}$ cells/well in $50 \mu \mathrm{L}$, white 384 -well plates. $4 \mathrm{~h}$ later, compounds or solvent were pinned from source plates, 4 pin dips/well in 3-fold serial dilutions spanning $68 \mathrm{nM}$ to $50 \mu \mathrm{M}$. After 3 days at $37{ }^{\circ} \mathrm{C}$, cell viability was assessed by CellTiter-Glo ${ }^{\circledR}$ (Promega), with viability for each cell line normalized to untreated control wells $(100 \%) ; n=4$ per compound. $\mathrm{SF}_{50}$ was determined in GraphPad Prism using $\log ($ dose $)$ response curve with variable slope.

Combination index - HEK293 cells were plated at $2 \times 10^{3}$ cells/well (50 $\mu \mathrm{L} /$ well) in columns $1-$ 22 of white 384 -well plates ( $n=4$ for each dose/dose combination); medium without cells was added to columns 23 and 24. Plates were incubated for 30 minutes at RT, then returned to $37^{\circ} \mathrm{C}$ for $4 \mathrm{~h}$. The interstrand-crosslink (ICL) agents (mitomycin $\mathrm{C}$ or cisplatin) and compound source plates were prepared in a diagonal ('ray') constant ratio combination design ${ }^{24}\left(\mathrm{SF}_{50}: \mathrm{SF}_{50}\right)$, with maximum concentration $8 \mathrm{x} \mathrm{SF}_{50}$, serially diluted in two-fold increments to minimum $0.0625 \mathrm{x} \mathrm{SF}_{50}$ (see Supp. Fig. 15 for details). After 3 days incubation at $37{ }^{\circ} \mathrm{C}$, plates were processed for CellTiter-Glo ${ }^{\circledR}$ as described above. Percent growth inhibition was calculated by normalizing 
luminescent signal at each dose condition to untreated control luminescence. Single compound and ICL agent dose effects (\% growth inhibition) were entered as fraction affected $(\mathrm{Fa}=1-(\%$ growth/100)) in CompuSyn (www.combosyn.com), software that determines iso-effect values, constructs isobolograms, and determines combination (interaction) indices ${ }^{24}$. Combination dose effects were entered for replicates of compound + ICL agent mixtures at constant ratios; $n \geq 4$ (range 4-8). Extremely low $(\mathrm{Fa}<0.01)$ or high $(\mathrm{Fa}>0.99)$ values were omitted from analysis, as recommended ${ }^{24}$.

ATPase selectivity assays - IC 50 values for ATPase activities of S. cerevisiae Rad54, Rdh54/Tid1, H. sapiens SMARCAL1, HLTF, VCP/p97 and E. coli RecA were determined by MG assay as described for RAD54, with modifications described in Supplement (Supp. Fig. 18).

\section{RESULTS AND DISCUSSION}

Cancer is frequently treated using combination approaches to target multiple molecular pathways that drive proliferation, malignancy, and/or resistance to first-line therapies ${ }^{25}$. Several arguments point to HR as a candidate target for therapeutic inhibition in cancer. First, during S-phase, proliferating cells prioritize HR above the alternative DSB repair pathway non-homologous endjoining (NHEJ) ${ }^{8}$, and HR aids DNA replication forks at template impasses or within complex genomic regions (e.g., repeats) ${ }^{26}$. Second, outside of HR, only single-strand annealing (SSA) between direct repeats can repair extensively resected ssDNA, presenting constraints for repair of resected ssDNA in cancer cells ${ }^{27}$. Third, chemotherapies and radiation cause DNA damage normally repaired by HR (e.g., interstrand crosslinks (ICLs), one-/two-ended DSBs, singlestranded gaps (Supp. Fig. 1)) ${ }^{28}$. Fourth, up to 15\% of cancers forestall chromosome shortening by Alternative Lengthening of Telomeres (ALT) ${ }^{29}$, an HR-dependent mechanism ${ }^{30}$; cancer cells 
relying on ALT are also hypersensitive to inhibition of ATR, an HR-affiliated kinase ${ }^{31}$. Finally, reactivation of HR leads to resistance in a number of BRCA2-deficient breast and ovarian cancers initially responsive to PARP inhibition ${ }^{32}$. HR inhibition therefore presents an opportunity for novel treatment mechanisms that selectively kill malignant cell populations or enhance therapeutic index in combination with other therapies.

We developed a multi-tiered strategy to identify small-molecule inhibitors of RAD54, a particularly attractive target for inhibition in HR because its ATPase activity specifically transitions the homologous pairing intermediate to an intermediate competent for DNA repair synthesis ${ }^{9}$. RAD54 inhibition in vivo would be expected to block HR progression at a late pathway step, accumulate futile recombination intermediates that are inadequately accomodated by alternative repair pathways, and enhance cytotoxic endpoints downstream of genotoxic damage or replication defects by trapping late pathway intermediates from further progression or reversal ${ }^{33}$.

\section{RAD54 inhibitor screen}

Malachite green assay. We developed a malachite green phosphate-detection assay in 384-well format to screen for small molecules that inhibit RAD54 ATPase activity in the presence of dsDNA (Supp. Fig. 2). Human RAD54 (hereafter RAD54) was purified as a GST-fusion from baculovirus-infected Sf9 cells. The MG assay was optimized for MG signal stability (Supp. Fig. 2) and enzyme activity (Supp. Fig. 3). Under the assay conditions (2.5 nM RAD54, $125 \mathrm{nM}$ (bp) pUC19, 1 mM ATP, 3 mM Mg(OAc) 2 , 0.1\% CHAPS, $30 \mu \mathrm{g} / \mathrm{mL}$ BSA, 25 mM HEPES, pH 7.5), phosphate production and MG signal were linear during the reaction time (13.5 minutes), with MG signal below saturation. In a pilot screen containing 1,995 bioactive compounds (MicroSource Spectrum), the signal/background was $80 \pm 11$ and $Z^{\prime}$ value was $0.87 \pm 0.02^{34}$. Hence, the assay 
showed excellent dynamic range and precision, indicating that even weak inhibitors should be detectable.

Hit identification. Having established that the MG assay quantitatively evaluates RAD54 ATPase activity, we performed a high-throughput screen (HTS) of 104,286 commercially sourced molecules. Compounds were screened at $10 \mu \mathrm{M}$. Due to a lower signal in the negative controls relative to the pilot screen, the overall $\mathrm{S} / \mathrm{B}$ ratio $=11 \pm 4.5$ and $\mathrm{Z}^{\prime}=0.74 \pm 0.06$ as determined by 10,688 negative (+DNA, DMSO vehicle only; $0 \pm 3.1 \%$ inhibition, median $=-0.1 \%$ ) and 10,688 positive (no DNA; $100 \pm 5.9 \%$ inhibition, median $=100 \%$ ) controls distributed across 334 assay plates (32 of each control per plate) (Fig. 1, Supp. Fig. 4). Across all 106,281 screened molecules, RAD54 inhibition spanned $-16.1 \%$ to $99.3 \%$ with mean inhibition of $-0.76 \pm 3.7 \%$ (median $=$ 1.1\%) (Fig. 1). We selected $310(0.3 \%)$ molecules with inhibition $\geq 17.7 \%$ ( $\geq 3$ s.d. from the mean of the $100 \%$ inhibition controls), with activities ranging from $17.7-99.3 \%$ inhibition (mean 38.98 $\pm 20.4 \%$ inhibition, median $=31 \%$ ).

The 310 active compounds were rescreened at seven doses in 2-fold serial dilution to determine the compound $\mathrm{IC}_{50}$ in both the $\mathrm{MG}$ assay and in a secondary ATPase assay, ADP-Glo ${ }^{\mathrm{TM}}$ (Promega). Assay performance was good for both formats. For MG, the signal/background was $7.5 \pm 1.2$ and $Z^{\prime}$ was $0.65 \pm 0.09$; for ADP-Glo ${ }^{\mathrm{TM}}$, the signal/background was 9 , with Z' value of 0.74 (ATP depletion $\leq 5 \%$ ) (Supp. Fig. 4 and data not shown). Compound $\mathrm{IC}_{50}$ values ranged from $<0.31 \mu \mathrm{M}$ to $>20 \mu \mathrm{M}$ in the $\mathrm{MG}$ assay $(14 \pm 7.1 \mu \mathrm{M}$, median $=20 \mu \mathrm{M})$ and from $<0.63 \mu \mathrm{M}$ to $>30 \mu \mathrm{M}$ in the ADP-Glo ${ }^{\mathrm{TM}}$ assay $(15 \pm 12 \mu \mathrm{M}$, median $=13 \mu \mathrm{M})$ (Fig. 1, Supp. Fig. 4). $\mathrm{IC}_{50}$ values measured in the ADP-Glo ${ }^{\mathrm{TM}}$ and $\mathrm{MG}$ assays generally correlated for tested compounds (Spearman $r=0.85$; Supp. Fig. 4), although compounds were typically more potent (lower $\mathrm{IC}_{50}$ ) 
in ADP-Glo ${ }^{\mathrm{TM}}$ assay. For 158 compounds, an $\mathrm{IC}_{50}$ could be determined in both the MG and ADPGlo ${ }^{\mathrm{TM}}$ assays, giving a $51 \%$ confirmation rate $(0.15 \%$ of compounds tested in primary screen).

To identify a potential structural basis for inhibition, we examined compounds for common scaffolds using SARvision Plus software. $>70 \%$ of active molecules binned into scaffold classes comprising $\geq 3$ compounds with $\geq 2$ rings (Supp. Table 1). An Excel document summarizing properties identified for the 158 hits is available at https://doi.org/10.7272/Q68G8HW8.

\section{Removal of DNA intercalators and PAINS}

DNA binding: DNA dependency of $\mathbf{I C}_{50}$. We next tested for potential artifacts among the confirmed hits by measuring nonspecific binding to DNA. Because RAD54 ATPase activity depended on direct interaction with dsDNA ${ }^{35,36}$, molecules that intercalated between stacked base pairs or within major or minor DNA grooves could have potentially interfered with RAD54 ATPase activity by altering dsDNA topology through a RAD54-independent mechanism. We confirmed that commercially available DNA-binding dyes interfered with RAD54 ATPase in vitro by determining $\mathrm{IC}_{50}$ values for ethidium, POPO-1, BOBO-1, TOTO-1, TOTO-3, YOYO-1, POPO3, BOPRO-3, DAPI, YOPRO-1, and SYTOX Orange in the MG assay (Supp. Fig. 5). All 11 molecules tested inhibited RAD54 ATPase; 8 dyes had IC $_{50}$ values $<200 \mathrm{nM}$, while YOPRO-1 had an $\mathrm{IC}_{50}$ value of $\sim 1 \mu \mathrm{M}$ and DAPI and BOPRO-3 had an $\mathrm{IC}_{50}$ greater than $1 \mu \mathrm{M}$ (the maximum concentration tested). DNA intercalators and groove binders can therefore be potent inhibitors of RAD54 ATPase activity and could lead to false positives in other screens of DNA-dependent ATPases. 
To exclude DNA intercalators from further analysis, we tested whether the apparent $\mathrm{IC}_{50}$ values of hits were sensitive to DNA concentration, rationalizing that molecules that interact with DNA would exhibit reduced inhibition of RAD54 ATPase when assayed at DNA concentration in excess of the screening concentration. In a pilot assay, increasing the DNA concentration by 160- or 1000-fold the screening concentration showed that the apparent $\mathrm{IC}_{50}$ values of ethidium and TOTO-1 were increased as a function of DNA concentration. The ratio between high and low DNA concentrations $\left(\mathrm{IC}_{50}{ }^{\mathrm{hi}} / \mathrm{IC}_{50}{ }^{\mathrm{lo}}\right.$ ) was $\sim 2.7$ for ethidium and $\sim 15$ TOTO-1 (Supp. Fig. 5).

We therefore assayed the 158 confirmed hits in the presence of $125 \mathrm{nM}$ bp pUC19 (DNA ${ }^{\text {lo. }}$ original screening concentration) and $125 \mu \mathrm{M}$ bp pUC19 (DNA ${ }^{\text {hi. }}$ 1,000x) (Fig. 2A). Based on their $\mathrm{IC}_{50}{ }^{\mathrm{hi}} / \mathrm{IC}_{50}{ }^{\text {lo }}$ ratios, hits were clustered into three principal classes with potentially distinct mechanisms of RAD54 inhibition (Fig. 2AB, Supp. Fig. 6). Class I compounds exhibited IC 50 values unchanged by DNA titration $\left(1.2<\mathrm{IC}_{50}{ }_{\mathrm{hi}} / \mathrm{IC}_{50}{ }^{\mathrm{lo}}<1.5\right)$; 92 compounds $(58 \%)$ were in this class. Class II compounds exhibited lower $\mathrm{IC}_{50}$ values in the presence of high DNA concentration $\left(\mathrm{IC}_{50}{ }_{\mathrm{hi}} / \mathrm{IC}_{50}{ }^{\mathrm{lo}}<1.2 ;\right.$ range $\left.=0.31-0.84\right) ; 28$ compounds $(17.7 \%)$ fell into this class. Finally, Class III compounds exhibited weaker $\mathrm{IC}_{50}$ values in the presence of high DNA concentration $\left(\mathrm{IC}_{50}{ }_{\mathrm{hi}} / \mathrm{IC}_{50}{ }^{\mathrm{lo}}>1.5\right.$, range $\left.=1.53-12.05\right) ; 38$ compounds $(24 \%)$ were identified as class III. We also confirmed that the DNA intercalators ethidium $\left(\mathrm{IC}_{50} \mathrm{hi} / \mathrm{IC}_{50}{ }^{\mathrm{lo}}=2.69\right)$ and mitoxantrone $\left(\mathrm{IC}_{50} \mathrm{hi} / \mathrm{IC}_{50}{ }^{\mathrm{lo}}\right.$ = 12) were Class III compounds (Fig. 2C).

TopoI inhibition. Rather than discount all 38 Class III compounds as non-specific, we applied a second filter based on E. coli Topoisomerase I (TopoI) relaxation of supercoiled pUC19 ${ }^{20}$ (Fig. 2E). Across a titration from $0.1-50 \mu \mathrm{M}, 18$ compounds (47\% of Class III) interfered with TopoI relaxation of supercoiled DNA at concentrations $\leq 50 \mu \mathrm{M}$ and were therefore excluded from further 
consideration. We also tested all remaining 120 compounds in Classes I and II at a single concentration $(50 \mu \mathrm{M})$. Surprisingly, we found that 14/92 (15\%) of Class I compounds and 10/28 $(36 \%)$ of Class II compounds also interfered with TopoI relaxation at this concentration; to avoid any nonspecific DNA intercalators, we also excluded these Class I and Class II from further consideration (Fig. 2F). For the 42 TopoI-interfering compounds from all three classes, the mean $\mathrm{IC}_{50}{ }^{\mathrm{hi}} / \mathrm{IC}_{50}{ }^{\mathrm{lo}}=2.4 \pm 2.4($ median $=1.2)$; for the remaining 116 that exhibited negligible TopoI inhibition, the mean $\mathrm{IC}_{50}{ }^{\mathrm{hi}} / \mathrm{IC}_{50}{ }^{\mathrm{lo}}=1.2 \pm 0.7($ median $=1.0)$, suggesting that Class designation by $\mathrm{IC}_{50}{ }^{\mathrm{hi}} / \mathrm{IC}_{50}{ }^{\mathrm{lo}}$ ratio was not predictive of TopoI inhibition.

Other assays to flag DNA intercalators have been described, including monitoring the loss of fluorescence polarization when acridine orange is displaced by competing DNA intercalators (Broad Institute, PubChem BioAssay AID 504727). In this report, 23\% of compounds were flagged as DNA intercalators, similar to the $24 \%$ we identified in the DNA titration assay and to the $27 \%$ identified in the TopoI assay. These observations emphasize the importance of including one or more counterscreen(s) to discard DNA intercalators as candidate inhibitors of DNAinteracting targets.

In sum, 116 out of 158 compounds (73\%) passed both filters for DNA interaction. Despite successful correlation of the $\mathrm{IC}_{50}$-DNA dependency assay with inhibition of TopoI activity on DNA, the TopoI relaxation assay is the most stringent filter for compounds that likely nonspecifically inhibit RAD54.

Reconfirmation of RAD54 inhibitors. Ultimately, 32 compounds that passed DNA intercalation filters (20\% of 158, 28\% of 116) were selected for follow-up (see doi:10.7272/Q68G8HW8): 16 compounds in Class I (17\% of 92), 8 compounds in Class II (29\% of 28$)$ and 8 compounds in Class 
III (21\% of 38) (Fig. 1), of which 26 (81\%) were commercially available (www.emolecules.com), purchased and/or resynthesized, tested for purity by LC/MS, and re-evaluated in MG and ADP$\mathrm{Glo}^{\mathrm{TM}}$ dose response assays. Eleven (42\%) repurchased or resynthesized compounds reconfirmed their original activity and were designated as RAD54 inhibitory (54i) molecules (Fig. 1, Supp. Table 5, 6, 7); 15 (58\%) repurchased or resynthesized compounds exhibited weak inhibition in MG and ADP-Glo ${ }^{\mathrm{TM}}$ assays ( $>60 \mu \mathrm{M}$ or $>20 \mu \mathrm{M}$, respectively) and were not considered to have recapitulated the inhibition initially observed in the primary screen. These 15 compounds (11 Class I, 4 Class III) were designated as RAD54 hits (h) in the primary screen $\left(^{\circ}\right)$ only $\left(54 \mathrm{~h}^{\circ}-1\right.$ through 15) and are not further described (Fig. 1, Supp. Table 7).

Exclusion of PAINS. High-throughput screens are vulnerable to pan-assay interfering chemotypes that show activity against a broad range of targets and across a variety of assay platforms by modalities that may include redox activity, fluorescence, metal ion chelation, aggregation, and/or non-specific, reversible or irreversible covalent protein binding ${ }^{23,29}$. We flagged PAINS among the 158 hits using three technologies: [1] in-house algorithms in HiTS, [2] publicly available Filter-it ${ }^{\mathrm{TM}}$ 1.0.2 and a PAINS sieve ${ }^{23}$, [3] Python script in commercially available OpenEye. HiTS flagged 88 of the 158 compounds $(56 \%, 9$ compounds mapped multiple substructures) as PAINS distributed among 21 recognized PAINS classes (Supp. Table 2, Supp. Fig. 7, doi:10.7272/Q68G8HW8), whereas Filter-it ${ }^{\mathrm{TM}}$ and a publicly available PAINS sieve flagged 63 compounds (40\% of hits, 18 recognized PAINS classes; Supp. Table 3) and OpenEye flagged 103 compounds (65\% of hits, 55 recognized PAINS classes, 83 that mapped to multiple substructures; Supp. Table 4, Supp. Fig. 8). Eighty-seven of the 116 hits that passed intercalation filters $(75 \%)$ were also flagged in HiTS as having Bruns-Watson Demerit scores $>10022$ (doi:10.7272/Q68G8HW8). The three technologies overlapped by more than $60 \%$ in flagging 
hits as PAINS (Supp. Fig. 9), but more complete and accurate PAINS substructure classifications made HiTS and OpenEye more comprehensive than Filter-It ${ }^{\mathrm{TM}}$ (OpenEye, however, flags additional substructures that are reported but not necessarily experimentally validated as PAINS (Supp. Fig. 9)). Notwithstanding the three computational algorithms to flag PAINS, toxoflavins were not flagged by any of the technologies, but rather by inspection (as they were discovered as a PAINS class subsequent to the original definition of PAINS substructure rules) ${ }^{37}$. The sizeable fraction of hits tagged as PAINS-like underscores the general importance of marking such molecules early in follow-up to HTS.

Among the eleven RAD54 inhibitory (54i) molecules, nine flagged as PAINS were notable for their generally low $\mathrm{IC}_{50}(\sim 1-15 \mu \mathrm{M}$, Supp. Table 5) and structural similarity and were included at risk in initial exploration of RAD54 inhibitors to cast a wide net; we ultimately discarded these to concentrate on mechanisms specific to interaction with RAD54 (these were designated as $54 \mathrm{i}^{\mathrm{P}}$ molecules and are not further described outside of Supplement (Supp. Fig. 11, 12, 14)). Our focus therefore proceeded with two molecules $(<0.002 \%$ of the library) classified as reproducible, authentic RAD54 inhibitors in vitro (54i compounds: 54i-1, 54i-2; Fig. 3). 54i-1 and 54i-2 are structurally distinct Class I compounds. Both meet Lipinski 'rule of 5' (RO5) guidelines for druglikeness (Supp. Table 6) ${ }^{38}$ and Veber ${ }^{39}$ and fSP3 hybridization ${ }^{40}$ correlations for toxicity and bioavailability (Supp. Fig. 10).

\section{Biochemical analysis of 54 i compounds}

We next set out to investigate the mechanism of inhibition for the reconfirmed RAD54 inhibitors. 54i compounds may inhibit RAD54 ATPase by reversibly or irreversibly interfering with i) RAD54/dsDNA binding or translocation, ii) RAD54 subunit interactions, or iii) ATP binding and hydrolysis. We evaluated reversibility/irreversibility of ATPase inhibition by pre-incubating 
RAD54 with compound at ten-fold excess to IC50, followed by 100 -fold dilution and release into ATPase assays with ATPase recovery monitored over time (so-called “jump dilution assay”, Fig. 3). We also evaluated interference with RAD54-dsDNA binding by monitoring equilibrium association of RAD54 with dsDNA across a 500-fold compound titration (0.1-50 $\mu \mathrm{M}$, Fig. 4). The two Class I compounds 54i-1 (a carbazole) and 54i-2 (an isoquinolyl piperidine) inhibit RAD54 by distinct mechanisms. $54 \mathrm{i}-1$ reversibly inhibits RAD54 with relatively low $\mathrm{IC}_{50}(5 \pm$ $1.05 \mu \mathrm{M})$, whereas 54i-2 irreversibly inhibits RAD54 with higher $\operatorname{IC}_{50}(16 \pm 3)$ (Fig. 3). 54i-1 does not appear to negate RAD54 binding to dsDNA, but rather provokes higher-order RAD54dsDNA complexes that are typically more favored at higher RAD54:bp ratios (retained in well); 54i-2, in contrast, interferes with RAD54 complex formation or stability in vitro (Fig. 4) ${ }^{41}$. While 54i-2 did not formally classify as PAINS with the filters used, it was judged to possess other unsavory features, such as potentially electrophilic sites and oxidation-prone ring systems, that make this particular compound less attractive as a starting point for further medicinal chemistry efforts.

We tested toxicity of the $54 \mathrm{i}$ cohort in a panel of immortalized cell lines of diverse tissue/tumor origin: embryonic kidney-derived HEK293; karyotypically normal mammary epithelium-derived MCF10A; mammary carcinomas MDA-MB-231, MCF7, HCC1806, and ZR-75-1; fibroblastderived VU423T $\left(B R C A 2^{-/}\right)$, A9.13.423 (VU423T with BRCA2 restored); osteosarcomas U2OS and Saos2 (both $A L T$ ); melanoma LOX; and fibrosarcoma HCT1080 (Supp. Table 9). 54i-2 exhibits broad toxicity to tested cell lines, whereas 54i-1 exhibits variable toxicity (Fig. 5, Supp. Table 10, Supp. Fig. 13). Similar to 54i-1 toxicity, cell line sensitivities to three tested genotoxins spanned a broad range of $\mathrm{SF}_{50}$ values, consistent with an expectation that cell type-specific molecular differences mediate diverse tolerance or sensitivity to ICLs (MMC and cisplatin) or 
PARP inhibition (olaparib). The sensitivity differences observed among tested cell lines are consistent with the broad range of genetic variation recognized in diverse immortalized cell types, and their differential sensitivities to radiation and other genotoxic therapeutics ${ }^{42}$.

When tested in combination with $\mathrm{MMC}$ and cisplatin over a 3-day simultaneous exposure protocol in HEK293, 54i-1 and 54i-2 exhibited CI values $<1$ (stronger effect for cisplatin than MMC), indicating synergism or potentiation with ICL genotoxins that increase demand for intact $\operatorname{HR}\left(Z^{\prime}\right.$ across all plates $=0.80 \pm 0.09$, range $=0.58-0.89 ; \mathrm{S} / \mathrm{B}=5 \pm 3.5$, range $\left.=4.2-5.6\right)($ Fig. 5,

Supp. Table 11, Supp. Fig. 16). Further work is needed to define whether the apparent combination interaction is explained by on-target compound interference with HR capacity to complete repair of ICL DNA damage. Importantly, HEK293 sensitivity to chronic ICL treatment is primarily due to proliferative arrest rather than cell death (Supp. Fig. 17), suggesting that acute ICL exposure followed by release into proliferative conditions in the presence of 54i compounds may better report on whether 54i compounds interfere with recovery from ICL exposure.

\section{Halogenated tricyclic fused heterocycles}

Among the two reproducible 54i hits that emerged from the HTS, 54i-1 (a halogenated carbazole) attracted interest because it does not appear to act as a DNA intercalator $\left(\mathrm{IC}_{50}\right.$ unaffected by DNA titration, no TopoI inhibition), its cellular toxicity varied across cell types, it mediates weak synergy with cisplatin in a combination assay under a simultaneous exposure protocol, and methods are readily available to prepare substituted carbazoles for evaluation of structure-activity relationships (SAR), selectivity and potency. A 54i-1 analog lacking chlorine atoms on the outer rings $\left(54 \mathrm{i}-1^{-2 \mathrm{Cl}}\right)$ exhibited ten-fold lower potency relative to $54 \mathrm{i}-1$, suggesting that a halogenated tricyclic ring system is a key pharmacophore of 54i-1 (Fig. 6A). 
To further explore the role of the tricyclic core and pendant side chain of 54i-1, we synthesized the known ${ }^{43}$ dihydroacridine analogs tricyc-1/2/3 (Fig. 6B), which bear gem-dimethyl substitution on the central six-membered ring and a pendant side-chain with acidic (tetrazole) rather than the basic functionality of 54i-1. We found that both the acidic side chain and non-planar dihydroacridine core were well tolerated and that halogenation of the distal aromatic rings was correlated with more potent $\mathrm{RAD} 54$ inhibition $\left(\mathrm{IC}_{50} \sim 3-7 \mu \mathrm{M}\right.$ halogenated [tricyc-2,3] vs. $>130$ $\mu \mathrm{M}$ non-halogenated [tricyc-1]) (Fig. 6B). These results suggest that RAD54 inhibition can be mediated by halogenated tricyclic fused heterocycles, and that for carbazole $54 \mathrm{i}-1$ this occurs by a mechanism distinct from DNA intercalation. While the intercalating ability of tricyc-1/2/3 was not explicitly evaluated, 9,9-dimethyl substitution in the central ring is predicted to disfavour if not rule out the possibility of DNA intercalation. In selectivity assays relative to other DNAdependent enzymatic activities that either do not translocate on dsDNA (e.g., HindIII) or that require DNA binding for ATP hydrolysis (e.g., SWI2/SNF2 ATPases $S$. cerevisiae RAD54, $S$. cerevesiae Rdh54, H. sapiens SMARCAL1, and H. sapiens HLTF; non-SWI2/SNF2 ATPases E. coli RecA and H. sapiens $\mathrm{VCP} / \mathrm{p} 97), 54 \mathrm{i}-1$ exhibited similar potency for RAD54 relative to its yeast Rad54 ortholog and for the related human SWI2/SNF2 ATPase SMARCAL1, 10-fold greater potency relative to its yeast Rdh54 homolog, $\sim 100$-fold greater potency relative to the related human SWI2/SNF2 ATPase HLTF and the unrelated human AAA ATPase VCP/p97, but nearly 5-fold lower potency relative to the unrelated E. coli ssDNA-dependent ATPase RecA (Fig. 6CD, Supp. Table 12). The differential selectivity among human SWI2/SNF2 ATPases, $\mathrm{VCP} / \mathrm{p} 97$, and RecA indicates that further improvements in selectivity can likely be achieved. In continued work, it will be important to complete binding kinetics (e.g., microscale thermophoresis) to test direct interaction and complete further structure-activity studies. 


\section{Prospects for HR inhibition}

The 54i molecules described here were identified in an effort to uncover chemotypes that interfere with a human HR-associated ATPase, RAD54. Because RAD51 and RAD54 ATPases collaborate in HR, inhibitors of either ATPase may have therapeutic applications in oncology. For RAD51, several reported small molecule modulators demonstrate that multiple biochemical activities of the enzyme can be altered (ssDNA binding, dsDNA binding, oligomerization) by covalent or noncovalent interactions, and can yield distinct mechanistic consequences to filament maturation (e.g., blocking ssDNA binding), homologous pairing or hDNA formation in vitro; some of these molecules reduce RAD51 foci in vivo, potentiating ICL sensitivity ${ }^{44}$. For RAD54, the mitomycin $\mathrm{C}$ - and actinomycin-related aminoquinone streptonigrin has been reported to inhibit the SWI2/SNF2 ATPase but not RAD51 ${ }^{45}$. Whether any RAD51- or RAD54-inhibiting compound specifically impairs HR in vivo, however, remains to be determined. Unlike RAD51, RAD54 and its paralog RAD54B engage in synthetic lethal interactions that suggest that their inhibition accumulates potentially toxic HR intermediates ${ }^{33,46}$. Like RAD51, RAD54 exhibits mechanistically separable biochemical activities that can be potentially targeted for interference, warranting continued efforts to identify distinct molecules that interfere with orthogonal functions such as DNA binding, oligomerization, ATPase activity, DNA translocation, and interaction/modulation by other factors like RAD51.

In sum, our screen for RAD54 ATPase inhibitors yielded two validated inhibitors of human RAD54. Although these compounds have potential limitations (toxicity, reactivity), the 54i molecules reported here (54i-1-2) represent novel structures that were vetted for DNA intercalation and PAINS. The activity of 54i-1 and tricyc-1-3 suggests that halogenated tricyclic heterocycles differentially inhibit human Swi2/Snf2 ATPases, and may merit analysis in assays 
that report on HR function in vivo. The screening strategy described here can be expanded to other small molecule libraries, and the ATPase assay is amenable to variations that include RAD51 as another cofactor modulating RAD54 ATPase. Further characterization of these and other RAD54 inhibitors - as well as small molecule inhibitors of other protein targets in HR - will enable direct tests of the hypothesis that HR inhibition may support cancer therapy.

\section{ACKNOWLEDGEMENTS}

We are grateful to Chris Wilson for valuable help and advice, Steven Chen for technical support and advice, Mark Burlingame for LC/MS analysis (Small Molecule Discovery Center, UCSF); Stephen Kowalcyzkowski for GST-RAD54-expressing baculovirus; Li Tao, Seyda Acar, Amitabh Nimonkar for Sf9 expression suggestions; Jeremy Stark, Anita Chen, Amanda Gunn (City of Hope, Duarte, CA) for mammalian cell culture training; Jodi Nunnari, Laura Lackner for SpectraMax M5 use; Hongwu Chen, Colleen Sweeney, Lifeng Xu for tumor cell lines; Stephen Kowalcyzkowsi for intercalator controls; Arianna Heyer for testing RAD54 compatibility with DMSO; Xiaoyan Ma for cell culture advice; Rita Alexeeva, Shannon Ceballos for pUC19 production and to all other members of the Heyer laboratory for discussion, resources and support; Stephen Kowalczykowski (UC Davis, CA), B.F. Eichman (Vanderbilt University, TN) for purified ATPase samples used in selectivity assays. 


\section{FUNDING}

This work was supported by United States Department of Defense (DoD) awards W81XWH-091-0116, W81XWH-14-1-0435 to W.-D. Heyer, W81XWH-14-1-036 to M.R. Arkin, and the QB3Malaysia Program to K.K.H. Ang.

\section{FIGURE LEGENDS}

Figure 1. Screen for small molecule inhibitors of RAD54 dsDNA-dependent ATPase. (A) Scatter-box plot representing high throughput screen (HTS) of 106,281 small molecules (gray) in the primary MG ATPase assay. S/B ratio $=11 \pm 4.5$ and $Z^{\prime}=0.74 \pm 0.06$ calculated from $\%$ inhibition values for positive controls (yellow, no ATPase activity) and negative controls (green, maximum ATPase activity) (10,688 replicates each). 310 compounds with $\geq 17 \%$ inhibition $(\geq 3$ s.d. from mean of negative controls) were evaluated for $\mathrm{IC}_{50}$ in both MG and ADP-Glo ${ }^{\mathrm{TM}}$ assays. (B) After two ATPase assays (colorimetric, MG and luminescent, ADP-Glo ${ }^{\mathrm{TM}}$ ) to identify inhibitors of RAD54 ATPase on dsDNA, 158 hits were further filtered by assays designed to flag likely DNA intercalators. Of the 116 compounds passed these filters, 32 were selected for repurchase/resynthesis and 26 were obtained. From these 26, 11 were designated as reproducibly authentic RAD54 inhibitors (54i) following rescreening. Two 54i compounds are structurally distinct; nine 54i compounds are pan-assay interfering structures (PAINS) in four structural scaffolds.

Figure 2. Filters to exclude probable DNA intercalators. (A) 158 compounds sort into three classes based on their $\mathrm{IC}_{50}$ dependency on DNA concentration: Class I ( $\mathrm{IC}_{50}$ not titratable by high 
DNA concentration), Class II ( $\mathrm{IC}_{50}$ reduced at high DNA concentration), Class III ( $\mathrm{IC}_{50}$ increased at high DNA concentration; predicted to be most consistent with DNA intercalator).

Compound distribution within three classes defined by $\mathrm{IC}_{50}$ ratio at two DNA concentrations, 125 $\mathrm{nM}$ ( 'lo') and $125 \mu \mathrm{M}$ bp (' $\left.h i^{\prime}\right)\left(\mathrm{IC}_{50}{ }^{\mathrm{hi}} / \mathrm{IC}_{50}{ }^{\mathrm{lo}}\right)$; $\mathrm{IC}_{50}$ ratio mean and s.d. are indicated for each class.

(C) Two known DNA intercalators, mitoxantrone and ethidium, were identified as Class III inhibitors with DNA-titratable $\mathrm{IC}_{50}$ (red points, $m$ and $e$, in $\mathrm{A} ; \mathrm{IC}_{50}{ }^{\text {hi }} / \mathrm{IC}_{50}$ lo in parentheses).

$\mathrm{IC}_{50}$ values at the screening DNA concentration $(125 \mathrm{nM}$ bp) in each class. (E) TopoI relaxes supercoiled DNA (pUC19) but its activity is inhibited by DNA intercalators (e.g., ethidium). Compounds were titrated up to $50 \mu \mathrm{M}$ into TopoI relaxation assays and pUC19 topoisomers were resolved by agarose gel electrophoresis to test directly for DNA intercalation (examples of Class I and III compounds are shown). Supercoiled pUC19 migrates further without drug than in the presence of an intercalator. Molecular weight marker is EZ Load $1 \mathrm{~kb}$ (BioRad). (F) The absolute number of compounds that do not inhibit (-) or inhibit TopoI activity $(+)$ plotted for each class, with the $\%$ of each class that is inhibitory to TopoI (inset).

Figure 3. Dose response and reversibility/irreversibility of RAD54 inhibition for 54i-1 and

54i-2. RAD54 inhibitory molecules with $\mathrm{RAD}_{4} \mathrm{IC}_{50}$ determined in the MG assay by a three-fold serial compound titration from $0.33-20 \mu \mathrm{M}$ (\% inhibition $v s . \log$ [compound]; $\mathrm{n}=4$ with mean and s.d. plotted). (A) 54i-1 (a carbazole); (B) 54i-2 (an isoquinolyl piperidine). Reversibility/irreversibility of RAD54 inhibition was determined by pre-incubating RAD54 with compound at ten-fold excess to the $\mathrm{IC}_{50}\left(10 \mathrm{x} \mathrm{IC}_{50}\right)$, followed by 100 -fold dilution into assay buffer containing compound at $10 x \mathrm{IC}_{50}$ (red, open circles/dashed line) or no compound (final assay concentration $=0.1 \times \mathrm{IC}_{50}$; red, closed circles/solid line) with sampling at time points up to two 
hours. Reversible inhibitor permits RAD54 activity to recover to uninhibited levels (black, closed squares/solid line); irreversible inhibitor renders RAD54 inactive to levels similar to the absence of DNA (black, open squares/dashed line). Class designation (green, Class I) and $\mathrm{IC}_{50}$ hi/ $\mathrm{IC}_{50}{ }^{\text {lo }}$ ratio (parentheses) are indicated.

Figure 4. Compound interference with RAD54-dsDNA interaction as a mechanism for ATPase inhibition. 54i-1-2 compounds were scored for interference with RAD54 binding to dsDNA by electrophoretic mobility shift assays. (A) schematic: RAD54-dsDNA binding and ATPase activity; RAD54-dsDNA binding in the presence or absence of ATP; (B) schematic: compound interference with RAD54-dsDNA binding equilibrium state; 54i-1 does not negate RAD54 binding to dsDNA (but rather appears to promote higher-order RAD54-dsDNA binding), whereas 54i-2 interferes with RAD54-dsDNA interaction across the compound titration. RAD54 was set to $25 \mathrm{bp}: 1$ RAD54 (monomer) and compounds were titrated from 0.1 to $50 \mu \mathrm{M}$.

Figure 5. Cell growth inhibitory effects of 54i-1-2, alone and in combination with ICL agents

MMC and cisplatin. $\mathrm{SF}_{50}$ across twelve cell lines for (A) 54i compounds and (B) ICL agents MMC and cisplatin. (C) Summary of $\mathrm{SF}_{50}$ distributions. $\mathrm{SF}_{50}$ was determined by CellTiter-Glo ${ }^{\mathrm{TM}}$ assay using a three-fold serial compound titration from $68 \mathrm{nM}$ to $50 \mu \mathrm{M}$ in twelve immortalized tumor lines ( $\mathrm{SF}_{50}$ determined as 50\% inhibition $v$ s. $\log$ [compound]; $\mathrm{n}=4$, mean and s.d. are plotted). Survival relative to untreated controls was determined three days after chronic incubation with compound; (D) Mean CI values of simultaneous treatment of compounds with ICL agents in HEK293 cells. Reported are CI values (mean + s.d.) at Fraction affected of 0.5, 0.75 and 0.9 for 
at least four replicates $(F a=1-(\%$ growth/100). CI values $\sim 1$ represent additive, $<1$ synergistic, or $>1$ antagonistic interactions ${ }^{24}$.

Figure 6. Halogenated tricyclic fused heterocycles (e.g., 54i-1) interfere with human SWI2/SNF2 ATPase activity. (A) $\mathrm{IC}_{50}$ determinations for 54i-1 and a non-chlorinated analog, $54 \mathrm{i}-1^{-2 \mathrm{Cl}}$; (B) $\mathrm{IC}_{50}$ determinations demonstrate that related dihydroacridines are inhibitory to RAD54, with ring halogenation preferred, as in the carbazole analogs; (C) Selectivity coefficients for non-RAD54 ATPases (IC 50 experimental ATPase/IC 50 RAD54), tested with 54i-1. Values $>1$ indicate greater potency for RAD54 relative to experimental ATPase; (E) Cladogram indicating relatedness among human and $S$. cerevisiae ATPases tested for selectivity (http://www.phylogeny.fr/) ${ }^{47}$.

\section{REFERENCES}

1. Li, X.; Heyer, W. D., Homologous recombination in DNA repair and DNA damage tolerance. Cell Res 2008, $18(1), 99-113$.

2. Haynes, B.; Saadat, N.; Myung, B.; Shekhar, M. P., Crosstalk between translesion synthesis, Fanconi anemia network, and homologous recombination repair pathways in interstrand DNA crosslink repair and development of chemoresistance. Mutat Res Rev Mutat Res 2015, 763, 258-66.

3. Srivastava, M.; Raghavan, S. C., DNA double-strand break repair inhibitors as cancer therapeutics. Chem Biol 2015, 22 (1), 17-29.

4. Chernikova, S. B.; Game, J. C.; Brown, J. M., Inhibiting homologous recombination for cancer therapy. Cancer Biol Ther 2012, 13 (2), 61-8.

5. Carvalho, J. F.; Kanaar, R., Targeting homologous recombination-mediated DNA repair in cancer. Expert Opin Ther Targets 2014, 18 (4), 427-58.

6. Kowalczykowski, S. C., An Overview of the Molecular Mechanisms of Recombinational DNA Repair. Cold Spring Harb Perspect Biol 2015, 7 (11).

7. Renkawitz, J.; Lademann, C. A.; Jentsch, S., Mechanisms and principles of homology search during recombination. Nat Rev Mol Cell Biol 2014, 15 (6), 369-83.

8. Heyer, W. D.; Ehmsen, K. T.; Liu, J., Regulation of homologous recombination in eukaryotes. Annu Rev Genet 2010, 44, 113-39.

9. Wright, W. D.; Heyer, W. D., Rad54 functions as a heteroduplex DNA pump modulated by its DNA substrates and Rad51 during D loop formation. Mol Cell 2014, 53 (3), 420-32. 
10. Ceballos, S. J.; Heyer, W. D., Functions of the Snf2/Swi2 family Rad54 motor protein in homologous recombination. Biochim Biophys Acta 2011, 1809 (9), 509-23.

11. Mazin, A. V.; Mazina, O. M.; Bugreev, D. V.; Rossi, M. J., Rad54, the motor of homologous recombination. DNA Repair (Amst) 2010, 9 (3), 286-302.

12.Li, X.; Zhang, X. P.; Solinger, J. A.; Kiianitsa, K.; Yu, X.; Egelman, E. H.; Heyer, W. D., Rad51 and Rad54 ATPase activities are both required to modulate Rad51-dsDNA filament dynamics. Nucleic Acids Res 2007, 35 (12), 4124-40.

13. Mazina, O. M.; Rossi, M. J.; Thomaa, N. H.; Mazin, A. V., Interactions of human rad54 protein with branched DNA molecules. J Biol Chem 2007, 282 (29), 21068-80.

14.Swagemakers, S. M.; Essers, J.; de Wit, J.; Hoeijmakers, J. H.; Kanaar, R., The human RAD54 recombinational DNA repair protein is a double-stranded DNA-dependent ATPase. J Biol Chem 1998, 273 (43), 28292-7.

15. Kiianitsa, K.; Solinger, J. A.; Heyer, W. D., Rad54 protein exerts diverse modes of ATPase activity on duplex DNA partially and fully covered with Rad51 protein. J Biol Chem 2002, 277 (48), 46205-15.

16. Pazin, M. J.; Kadonaga, J. T., SWI2/SNF2 and related proteins: ATP-driven motors that disrupt proteinDNA interactions? Cell 1997, 88 (6), 737-40.

17. Mazin, A. V.; Mazina, O. M.; Bugreev, D. V.; Rossi, M. J., Rad54, the motor of homologous recombination. DNA Repair 2010, 9 (3), 286-302.

18.Rowlands, M. G.; Newbatt, Y. M.; Prodromou, C.; Pearl, L. H.; Workman, P.; Aherne, W., Highthroughput screening assay for inhibitors of heat-shock protein 90 ATPase activity. Anal Biochem 2004, $327(2), 176-83$.

19. Mazina, O. M.; Mazin, A. V., Human Rad54 protein stimulates DNA strand exchange activity of hRad51 protein in the presence of Ca2+. J Biol Chem 2004, 279 (50), 52042-51.

20.Peixoto, P.; Bailly, C.; David-Cordonnier, M. H., Topoisomerase I-mediated DNA relaxation as a tool to study intercalation of small molecules into supercoiled DNA. Methods Mol Biol 2010, 613, 235-56.

21. Rajarshi, G. PAINS Substructure Filters as SMARTS. So much to do, so little time: Trying to squeeze sense out of chemical data. http://blog.rguha.net/?p=850 (accessed October 10).

22. Bruns, R. F.; Watson, I. A., Rules for identifying potentially reactive or promiscuous compounds. $J$ Med Chem 2012, 55 (22), 9763-72.

23. Baell, J. B.; Holloway, G. A., New substructure filters for removal of pan assay interference compounds (PAINS) from screening libraries and for their exclusion in bioassays. J Med Chem 2010, 53 (7), 2719-40.

24. Chou, T. C., Theoretical basis, experimental design, and computerized simulation of synergism and antagonism in drug combination studies. Pharmacol Rev 2006, 58 (3), 621-81.

25. Glickman, M. S.; Sawyers, C. L., Converting cancer therapies into cures: lessons from infectious diseases. Cell 2012, 148 (6), 1089-98.

26.Syeda, A. H.; Hawkins, M.; McGlynn, P., Recombination and replication. Cold Spring Harb Perspect Biol 2014, 6 (11), a016550.

27.Feng, Z.; Scott, S. P.; Bussen, W.; Sharma, G. G.; Guo, G.; Pandita, T. K.; Powell, S. N., Rad52 inactivation is synthetically lethal with BRCA2 deficiency. Proc Natl Acad Sci U S A 2011, 108 (2), 686-91. 28. Deans, A. J.; West, S. C., DNA interstrand crosslink repair and cancer. Nat Rev Cancer 2011, 11 (7), 467-80.

29. Baell, J.; Walters, M. A., Chemistry: Chemical con artists foil drug discovery. Nature 2014, 513 (7519), 481-3.

30. Heyer, W. D., Regulation of recombination and genomic maintenance. Cold Spring Harb Perspect Biol 2015, 7 (8), a016501. 
31.Flynn, R. L.; Cox, K. E.; Jeitany, M.; Wakimoto, H.; Bryll, A. R.; Ganem, N. J.; Bersani, F.; Pineda, J. R.; Suva, M. L.; Benes, C. H.; Haber, D. A.; Boussin, F. D.; Zou, L., Alternative lengthening of telomeres renders cancer cells hypersensitive to ATR inhibitors. Science 2015, 347 (6219), 273-7.

32. Bouwman, P.; Jonkers, J., Molecular pathways: how can BRCA-mutated tumors become resistant to PARP inhibitors? Clin Cancer Res 2014, 20 (3), 540-7.

33.Zinovyev, A.; Kuperstein, I.; Barillot, E.; Heyer, W. D., Synthetic lethality between gene defects affecting a single non-essential molecular pathway with reversible steps. PLoS Comput Biol 2013, 9 (4), e1003016.

34.Zhang, J. H.; Chung, T. D.; Oldenburg, K. R., A Simple Statistical Parameter for Use in Evaluation and Validation of High Throughput Screening Assays. J Biomol Screen 1999, 4 (2), 67-73.

35.Solinger, J. A.; Lutz, G.; Sugiyama, T.; Kowalczykowski, S. C.; Heyer, W. D., Rad54 protein stimulates heteroduplex DNA formation in the synaptic phase of DNA strand exchange via specific interactions with the presynaptic Rad51 nucleoprotein filament. J Mol Biol 2001, 307 (5), 1207-21.

36.Tan, T. L.; Essers, J.; Citterio, E.; Swagemakers, S. M.; de Wit, J.; Benson, F. E.; Hoeijmakers, J. H.; Kanaar, R., Mouse Rad54 affects DNA conformation and DNA-damage-induced Rad51 foci formation.

Curr Biol 1999, 9 (6), 325-8.

37. Baell, J. B.; Nissink, J. W. M., Seven Year Itch: Pan-Assay Interference Compounds (PAINS) in 2017Utility and Limitations. ACS Chem Biol 2018, 13 (1), 36-44.

38. Lipinski, C. A., Lead- and drug-like compounds: the rule-of-five revolution. Drug Discov Today Technol 2004, 1 (4), 337-41.

39.Veber, D. F.; Johnson, S. R.; Cheng, H. Y.; Smith, B. R.; Ward, K. W.; Kopple, K. D., Molecular properties that influence the oral bioavailability of drug candidates. J Med Chem 2002, 45 (12), 2615-23. 40. Lovering, F.; Bikker, J.; Humblet, C., Escape from flatland: increasing saturation as an approach to improving clinical success. J Med Chem 2009, 52 (21), 6752-6.

41. Copeland, R. A., Evaluation of Enzyme Inhibitors in Drug Discovery: A Guide for Medicinal Chemists and Pharmacologists. 1 ed.; John Wiley \& Sons, Inc.: 2003.

42.Yard, B. D.; Adams, D. J.; Chie, E. K.; Tamayo, P.; Battaglia, J. S.; Gopal, P.; Rogacki, K.; Pearson, B. E.; Phillips, J.; Raymond, D. P.; Pennell, N. A.; Almeida, F.; Cheah, J. H.; Clemons, P. A.; Shamji, A.; Peacock, C. D.; Schreiber, S. L.; Hammerman, P. S.; Abazeed, M. E., A genetic basis for the variation in the vulnerability of cancer to DNA damage. Nat Commun 2016, 7, 11428.

43. Bagriantsev, S. N.; Ang, K. H.; Gallardo-Godoy, A.; Clark, K. A.; Arkin, M. R.; Renslo, A. R.; Minor, D. L., Jr., A high-throughput functional screen identifies small molecule regulators of temperature- and mechano-sensitive K2P channels. ACS Chem Biol 2013, 8 (8), 1841-51.

44. Huang, F.; Mazin, A. V., Targeting the homologous recombination pathway by small molecule modulators. Bioorg Med Chem Lett 2014, 24 (14), 3006-13.

45. Deakyne, J. S.; Huang, F.; Negri, J.; Tolliday, N.; Cocklin, S.; Mazin, A. V., Analysis of the activities of RAD54, a SWI2/SNF2 protein, using a specific small-molecule inhibitor. J Biol Chem 2013, 288 (44), 31567-80.

46. McManus, K. J.; Barrett, I. J.; Nouhi, Y.; Hieter, P., Specific synthetic lethal killing of RAD54B-deficient human colorectal cancer cells by FEN1 silencing. Proc Natl Acad Sci U S A 2009, 106 (9), 3276-81.

47.Dereeper, A.; Guignon, V.; Blanc, G.; Audic, S.; Buffet, S.; Chevenet, F.; Dufayard, J. F.; Guindon, S.; Lefort, V.; Lescot, M.; Claverie, J. M.; Gascuel, O., Phylogeny.fr: robust phylogenetic analysis for the non-specialist. Nucleic Acids Res 2008, 36 (Web Server issue), W465-9. 


\section{Figure 1}

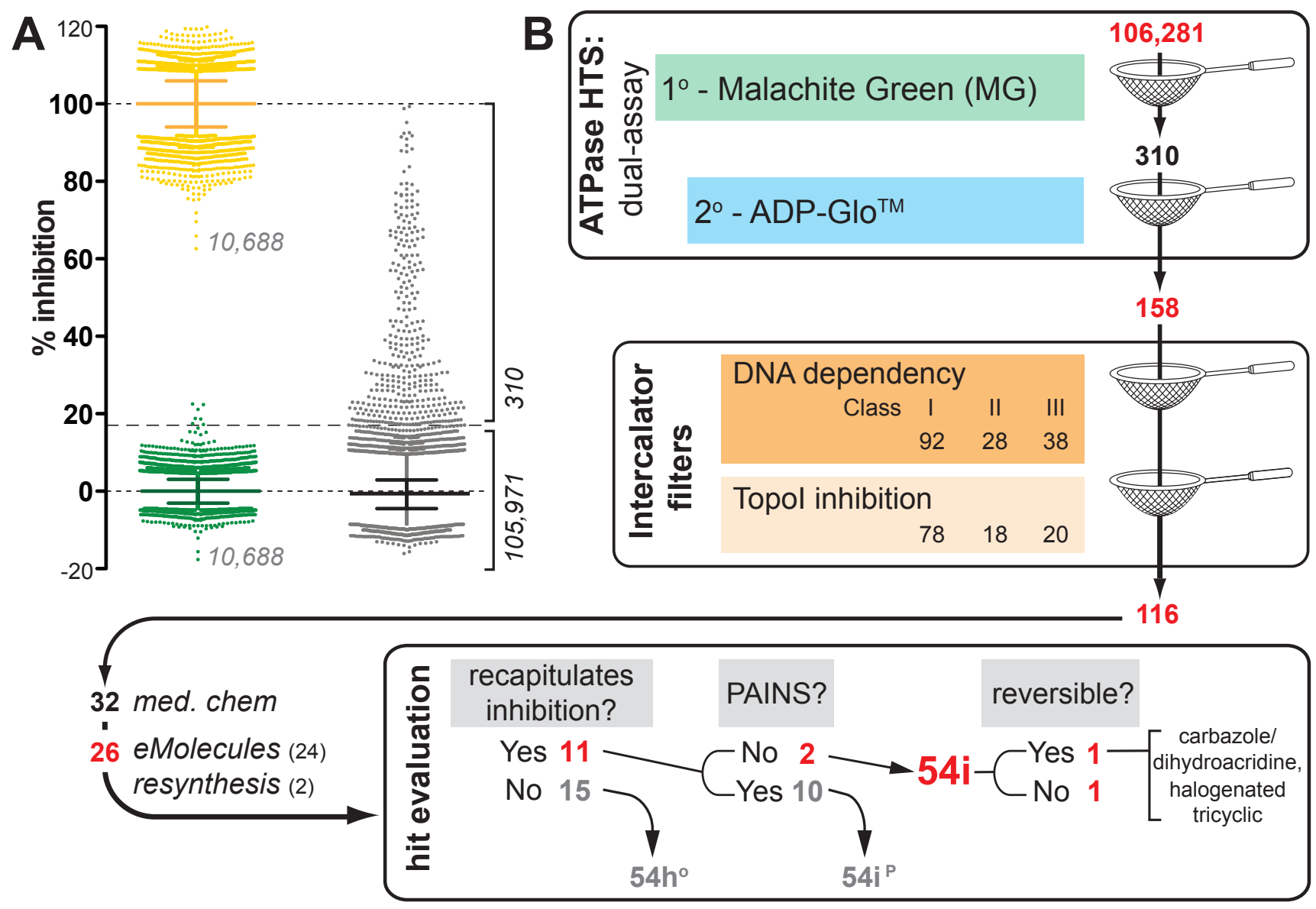


bioRxiv preprint doi: https://doi.org/10.1101/614586; this version posted April 19 2019. The copyright holder for this preprint (which was not certified by peer review) is the author/funder, who has granted bioRxiv a license to display the preprint in perpetuity. It is made available under aCC-BY-NC-ND 4.0 International license.

Figure 2

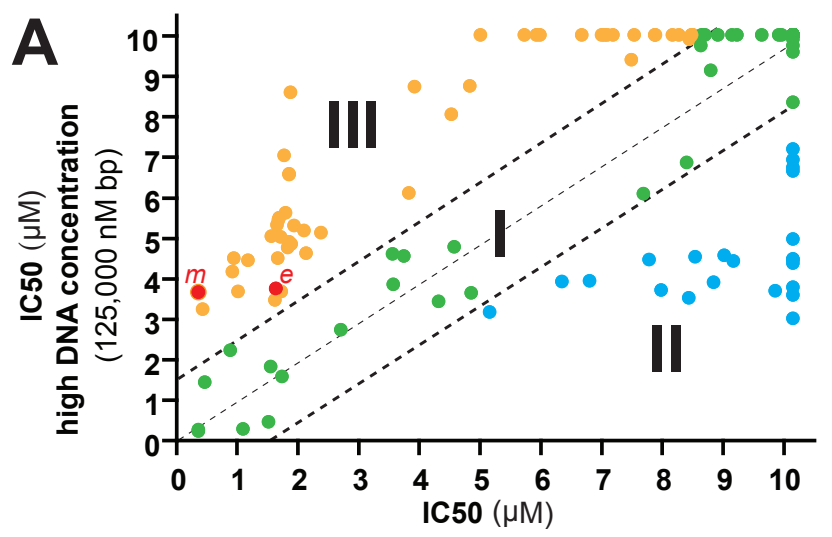

Iow DNA concentration (125 nM bp)

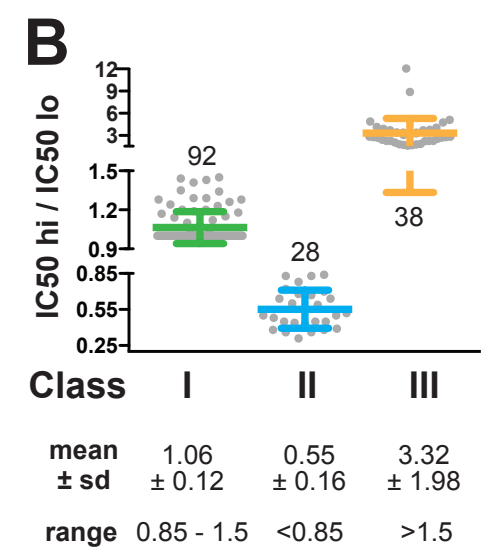

C
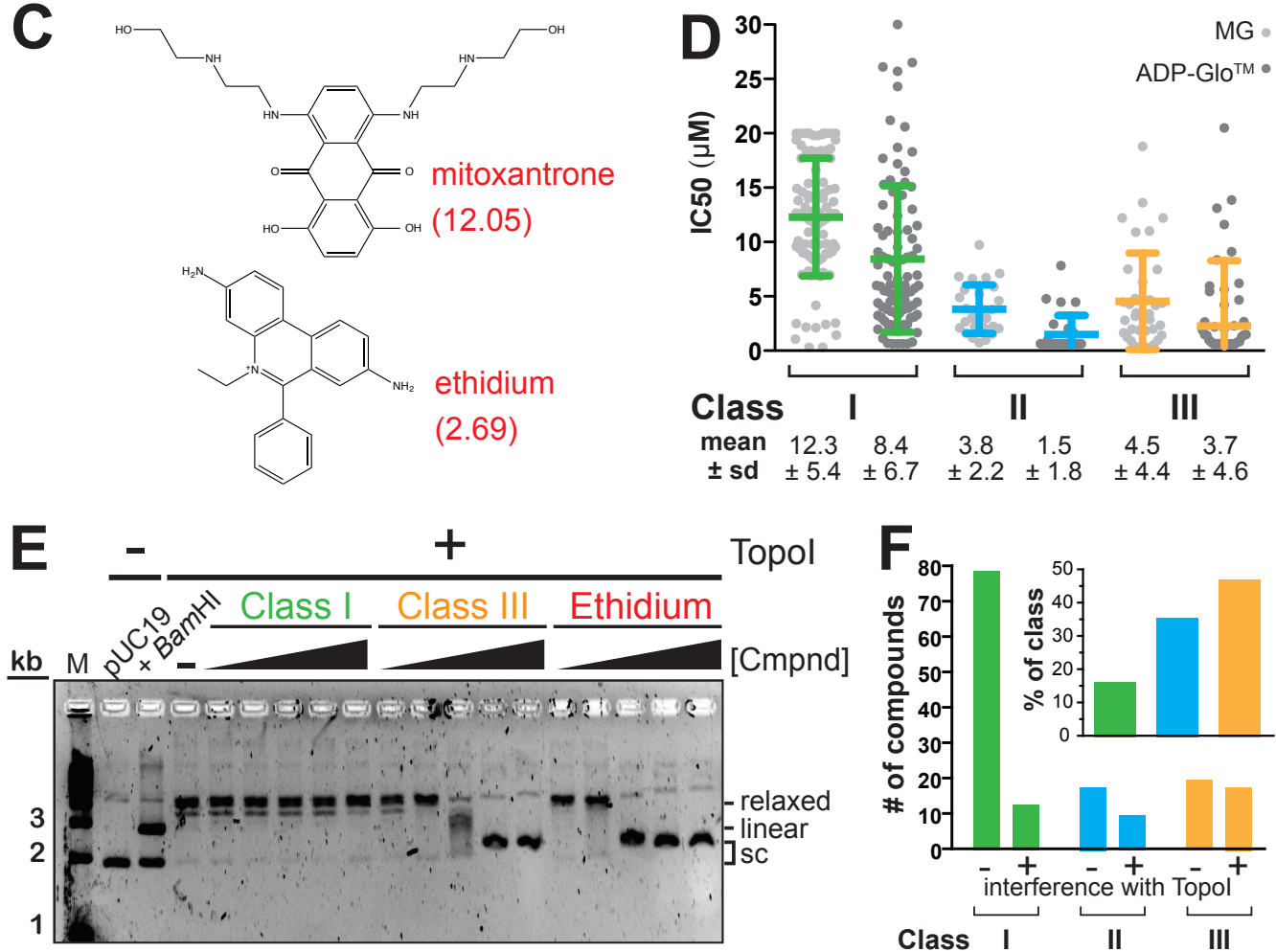

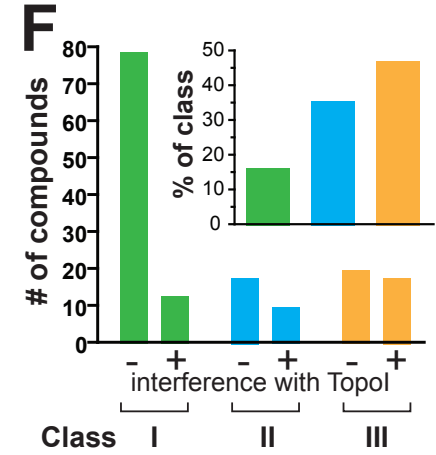


bioRxiv preprint doi: https://doi.org/10.1101/614586; this version posted April 19, 2019. The copyright holder for this preprint (which was not certified by peer review) is the author/funder, who has granted bioRxiv a license to display the preprint in perpetuity. It is made available under aCC-BY-NC-ND 4.0 International license.

\section{Figure 3}

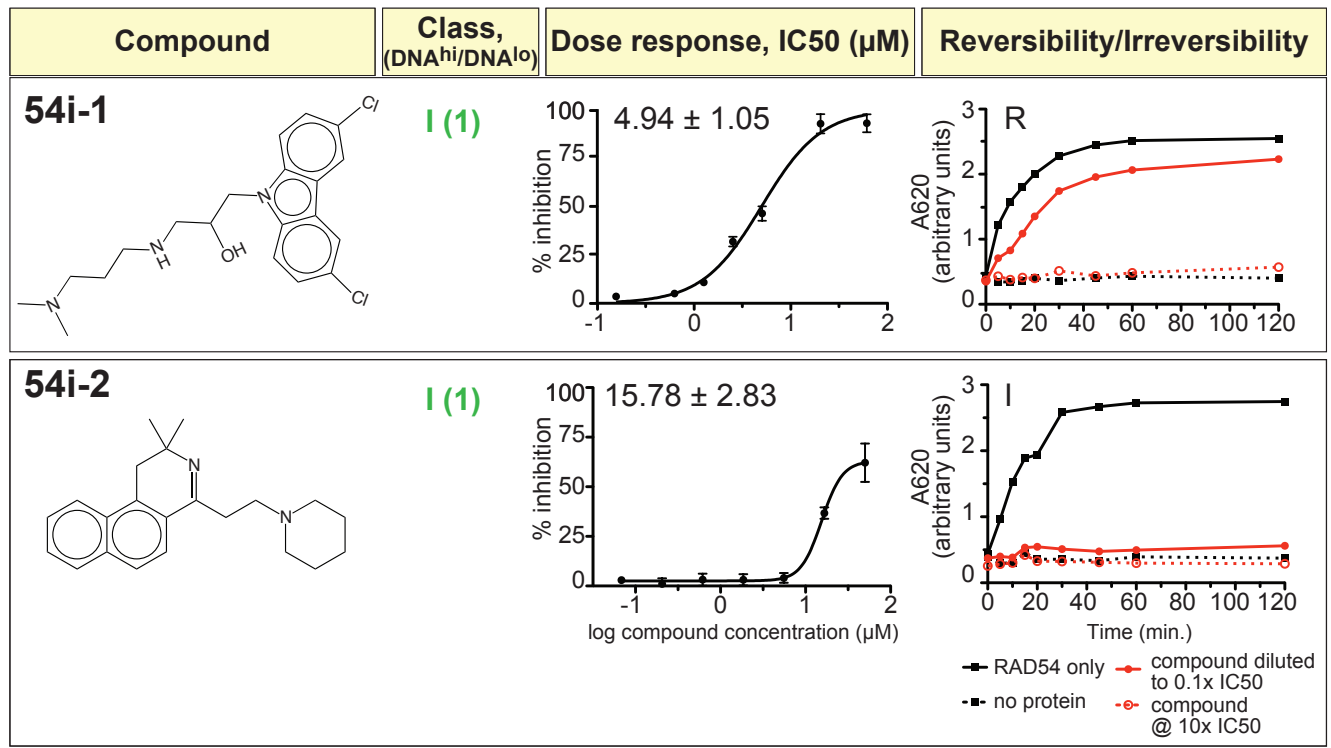


bioRxiv preprint doi: https://doi.org/10.1101/614586; this version posted April 19, 2019. The copyright holder for this preprint (which was not certified by peer review) is the author/funder, who has granted bioRxiv a license to display the preprint in perpetuity. It is made available under aCC-BY-NC-ND 4.0 International license.

Figure 4

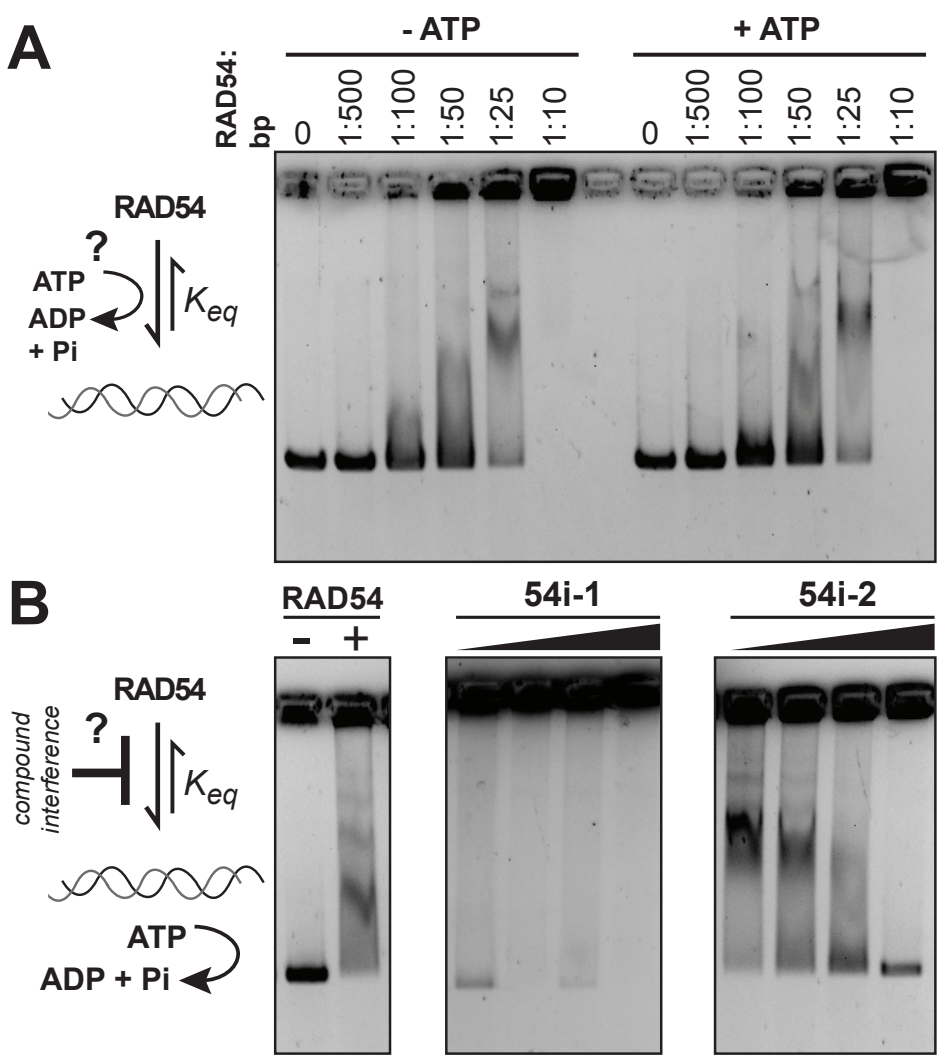


Figure 5

A
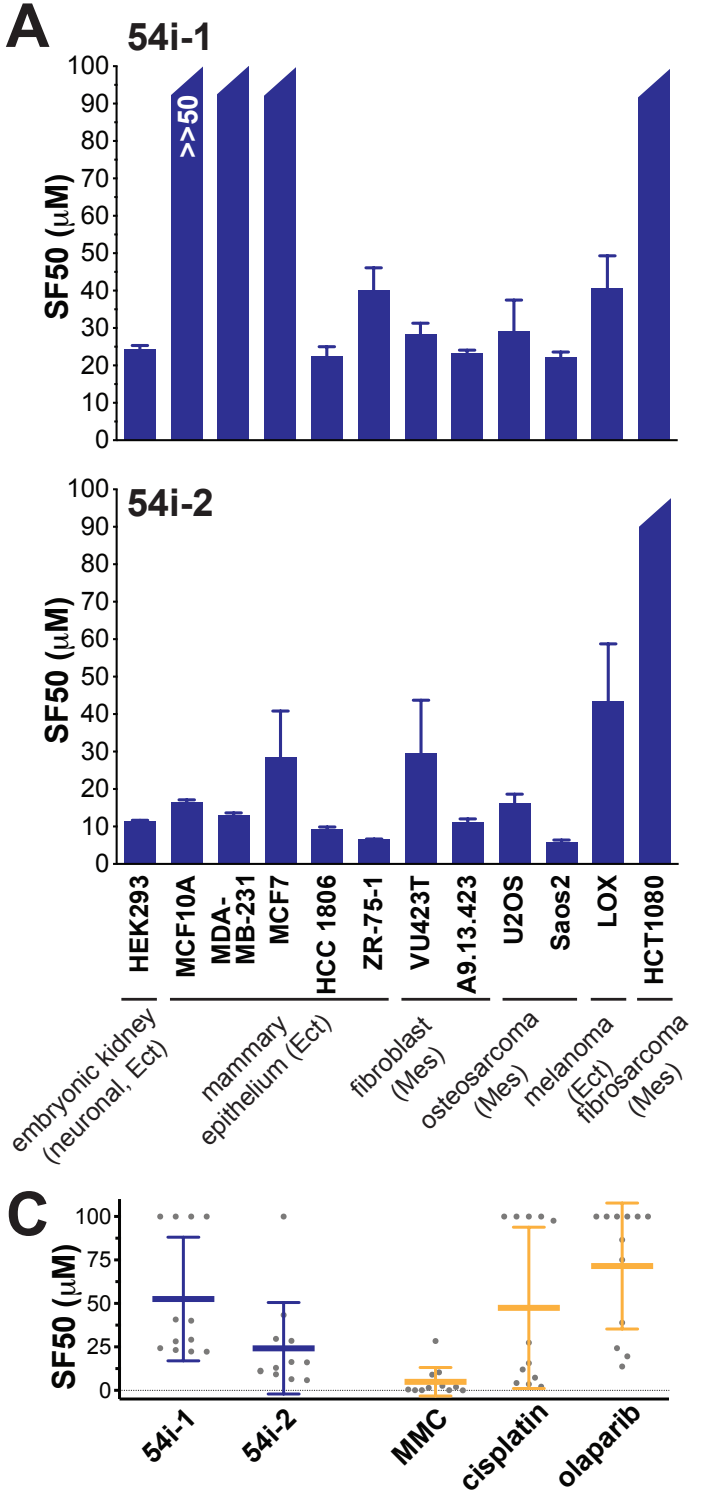

B
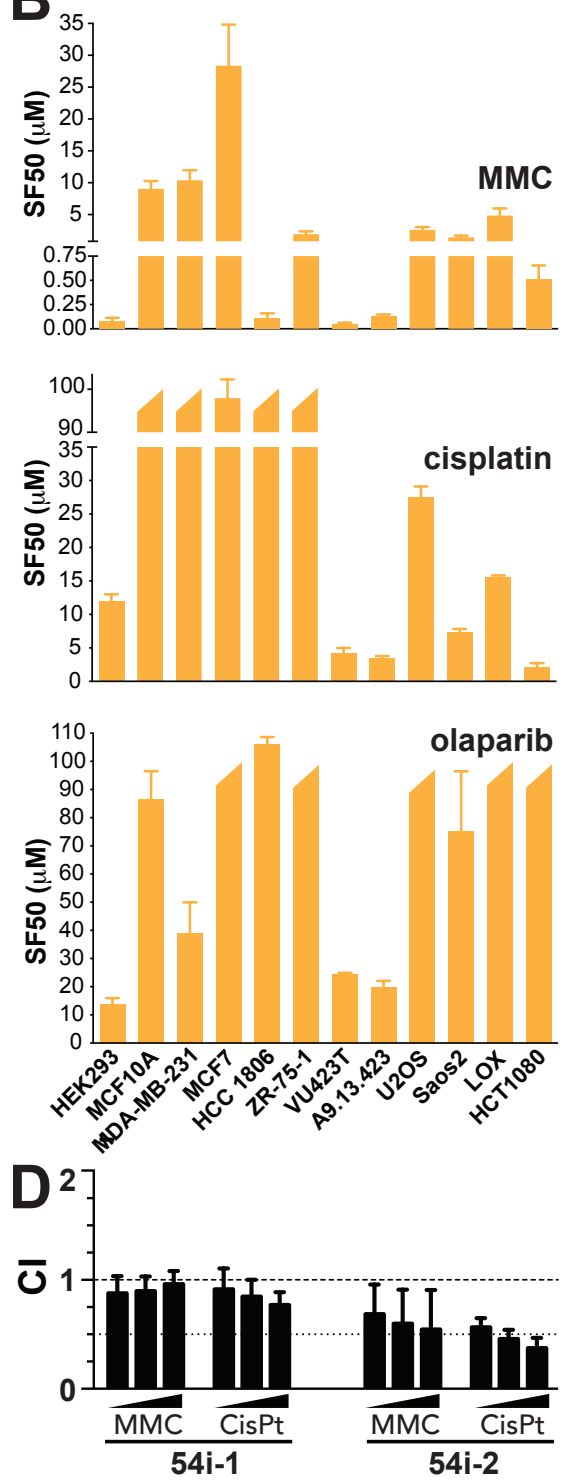


\section{Figure 6}
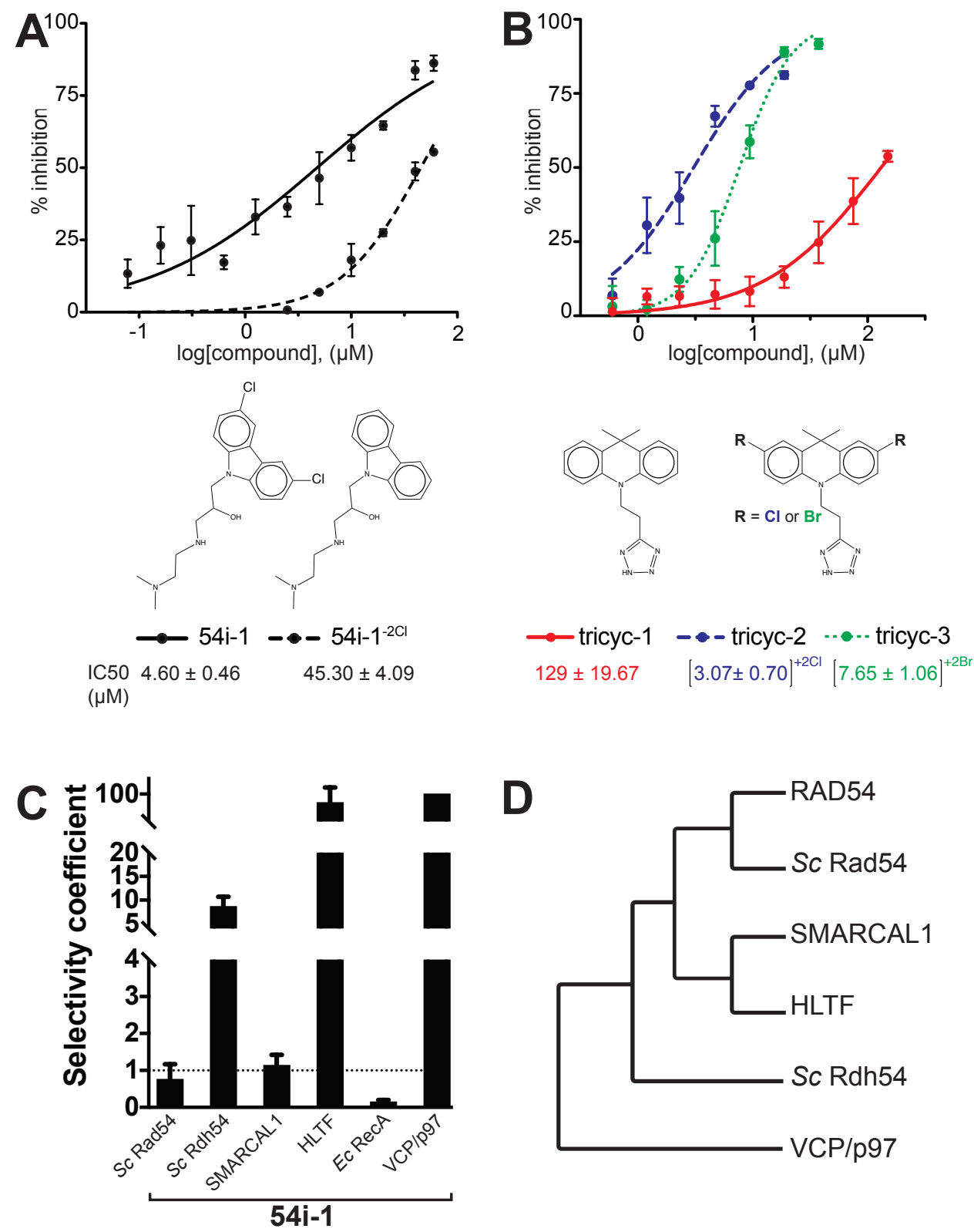

$54 i-1$ 